\title{
A Novel Partially Biobased PAN-Lignin Blend as a Potential Carbon Fiber Precursor
}

\author{
M. Özgür Seydibeyoğlu \\ Department of Materials Science and Engineering, Izmir Katip Celebi University, Faculty of Engineering and Architecture, \\ 35620 Izmir, Turkey \\ Correspondence should be addressed to M. Özgür Seydibeyoğlu, seydibey@gmail.com
}

Received 8 June 2012; Revised 8 August 2012; Accepted 8 August 2012

Academic Editor: Anuj K. Chandel

Copyright (๑) 2012 M. Özgür Seydibeyoğlu. This is an open access article distributed under the Creative Commons Attribution License, which permits unrestricted use, distribution, and reproduction in any medium, provided the original work is properly cited.

Blends of polyacrylonitrile (PAN) and lignin were prepared with three different lignin types by solution blending and solution casting. Among three types of lignin, one type was chosen and different blend concentrations were prepared and casted. The casted blend films were characterized chemically with fourier transform infrared spectroscopy (FTIR), and thermally with thermogravimetric analysis (TGA). The mechanical properties of the blends were measured using dynamic mechanical analysis (DMA). FTIR analysis shows an excellent interaction of PAN and lignin. The interaction of the lignins and PAN was confirmed by TGA analysis. The DMA results reveal that the lignin enhance the mechanical properties of PAN at room temperature and elevated temperatures. The blend structure and morphology were observed using scanning electron microscopy (SEM). SEM images show that excellent polymer blends were prepared. The results show that it is possible to develop a new precursor material with a blend of lignin and PAN. These studies show that the side product of paper and cellulosic bioethanol industries, namely, lignin can be used for new application areas.

\section{Introduction}

Carbon fibers attract attention throughout the world as a strong and light material in the composites industry for applications such as aerospace, automotive, and renewable energy resources [1]. For the fiber reinforced composites, carbon fibers are excellent reinforcing materials with mechanical strength of $5000 \mathrm{MPa}$, modulus value of $250 \mathrm{GPa}$, and density of $1.76 \mathrm{~g} / \mathrm{cm}^{3}$. Carbon fiber was first invented in 1871 by using cellulose as the precursor but the industrial applicable carbon fiber was developed in the 1960's by Union Carbide. In the beginning of 1970's, the use of carbon fibers for aerospace and military applications started [1]. Besides superior specific strength (strength/density), carbon fibers exhibit excellent properties in electrical conductivity, shielding effects, and heat resistance [1].

For the production of carbon fibers, there are three main raw materials, precursors. The first one is the cellulose which was first used in 1871. Pitch and polyacrylonitrile (PAN) are two other materials to produce carbon fibers. Due to the final fiber properties obtained, carbon fiber produced from PAN is commonly used which contributes $90 \%$ of the total carbon fibers available in the market $[2,3]$.

The production capacity of carbon fiber is increasing with new composite manufacturing techniques in the world, thus the need for composites and carbon fibers is increasing. However the price of carbon fiber is not declining which limits the widespread use of carbon fibers [4]. One of the reasons for the high cost of the carbon fiber is the precursor material. The research for precursor material is limited in the academy and the research findings from PAN producers are not available in the public press. In the current carbon fiber industry, still the price of the precursor is one of the obstacles to get a widespread use of carbon fiber [5].

The precursor material, PAN is a terpolymer of acrylonitrile, vinyl acetate and itaconic acid. The precursor is prepared with different processing stages including polymerization, PAN-solvent (dimethylacetamide) mixture preparation, and fiber spinning. After obtaining PAN precursor, the fibers are transformed to carbon fiber via oxidation 
and carbonization processes followed by certain surface treatments [1].

To reduce the cost of precursor material, PAN polymer is blended with lignin in this study. Lignin is the third most abundant polymer on earth that is available from all the plants. The amount of lignin that is available is 300 billion tones [6]. Lignin constitutes $25-35 \%$ of the plants depending on the plant type [7]. With so many different plants there is much lignin resource.

On the other hand, lignin is generally removed during paper manufacturing and lignocellulosic bioethanol production. These industries are trying to find ways to obtain pure cellulose to achieve the highest quality by a process called delignification. Thus, lignin has been undervalued in these processes and it is not even considered as a coproduct [8]. Lignin is used as a fuel by burning at elevated temperatures [9]. However, the efficiency of lignin burning is limited. There are other studies conducted to prepare new materials with lignin. There are many studies reported on the polymer blend manufacturing with lignin and some other polymers [8]. There are studies to synthesize polyurethanes with lignin as the polyol [10]. The lignin finds applications as surfactant, ultraviolet stabilizers, dyes, and colorants [8].

Lignin was used to prepare carbon fibers as well. The research on carbon fibers with lignin is very limited due to the poor properties obtained with neat lignin material [ 11 , 12]. The tensile strength values obtained are in the range of 600-700 MPa which is very low compared to a conventional carbon fiber, thus it cannot be used as the reinforcing fiber.

In this study a novel biobased precursor material was prepared via blending PAN and lignin in order to reduce the cost of precursor, to improve the mechanical properties of precursor and to find new applications of lignin which is undervalued product and moreover to create a sustainable, renewable biobased material. Due to price of carbon fiber, the demand for carbon fiber is not that high. This study demonstrates that it is feasible to reduce the cost of the carbon fiber precursor with the use of side product from cellulosic ethanol and paper industries. The lignin materials and blend morphology were investigated with scanning electron microscopy. Mechanical performance of the blends was measured to understand the effects of lignin for the PAN polymer. Furthermore, the interaction of PAN and lignin was analyzed using FTIR and TGA. SEM images were obtained to understand the blend morphology.

\section{Experimental}

2.1. Materials. PAN (polyacrylonitrile) was purchased from Acordis Kelheim GmBH as Homo-PAN in the form powder. Three types of lignin (Protobind 1000, Protobind 5000, and Protobind 2400) were obtained from Greenvalue as a gift. Detailed chemical and thermal analyses of the lignin from Greenvalue were done in a previous publication [6]. Dimethyl acetamide (DMAc) solvent was analytical grade.

2.2. Sample Preparation. Blends of PAN and lignin were prepared with solution casting technique. The lignin and PAN
TABLE 1: Sample codes.

\begin{tabular}{lcc}
\hline Sample code & PAN wt\% & Lignin type, wt $\%$ \\
\hline PAN & 100 & 0 \\
PL1020 & 80 & Protobind 1000, 20 \\
PL2420 & 80 & Protobind 2400, 20 \\
PL5020 & 80 & Protobind 5000, 20 \\
PL2410 & 90 & Protobind 2400, 10 \\
PL2430 & 70 & Protobind 2400, 30 \\
\hline
\end{tabular}

were dissolved in DMAc at certain weight percentages. The PAN-lignin solution was stirred overnight and the solution was cast onto glass. The solution was placed in an oven at $120^{\circ} \mathrm{C}$ for 6 hours to evaporate DMAc. After removing the solvent, films of the PAN-lignin blends were peeled from the glass surface. Table 1 shows the weight percentages of the blends and the sample codes.

2.3. Characterization. Optical microscopy image was obtained using Leica DM $1750 \mathrm{M}$ with 500x magnification. Scanning electron microscopy (SEM) was used to observe the microstructure of the polymer blends. JEOL 640 was used as SEM. The samples were coated with gold and the images were taken at different magnifications.

Fourier transform infrared analysis (FTIR) was done with Perkin Elmer, model spectrum 2000 with ATR mode. The spectrometer was used with transmission mode and the resolution was $4 \mathrm{~cm}^{-1}$ with a range of $400-4000 \mathrm{~cm}^{-1}$. Thermogravimetric analysis (TGA) was carried with Perkin Elmer Diamond TG/DTA by heating from room temperature to $600^{\circ} \mathrm{C}$ under nitrogen atmosphere. Dynamic mechanical analysis (DMA) was carried with Dynatest Metravib with tensile clamps heating from room temperature to $200^{\circ} \mathrm{C}$ with a frequency of $1 \mathrm{~Hz}$.

\section{Results and Discussion}

3.1. Microscopy. Microscopy is the essential part of materials science research showing the particles, polymers and their interaction. The microscopy studies demonstrate the particle size, morphology and their change after polymer blending and composite preparation. Optical microscopy enables researchers to observe the preliminary images easily with no sample preparation needed [13]. Moreover, OM provides the actual images with colors. Scanning electron microscopy gives more detailed information by the electron emission and collecting the image via back scattering of the electrons [14]. In this study, lignin particles were investigated with optical microscopy (OM) and scanning electron microscopy (SEM). Blends of PAN and lignin were investigated with SEM.

Lignin Particles. The OM was used to get the images of lignin particles (Protobind 2400) as shown in Figure 1. The OM images of lignin particles have not been published before. Lignin particles are brown in color and they are semitransparent by their nature. This is highly important for many composites which will be made with lignin especially 


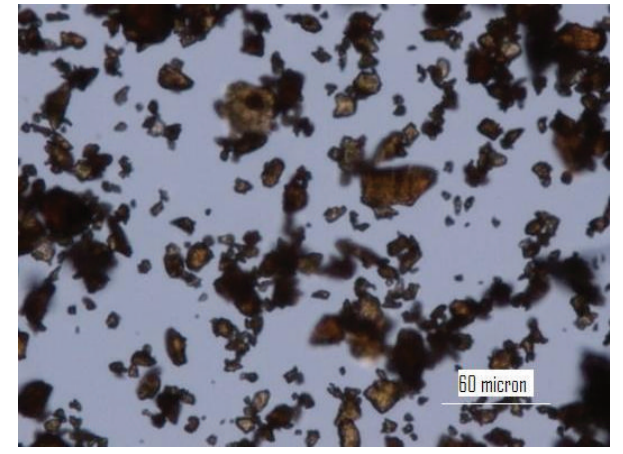

FIgURE 1: Optical microscopy image of Protobind 2400.

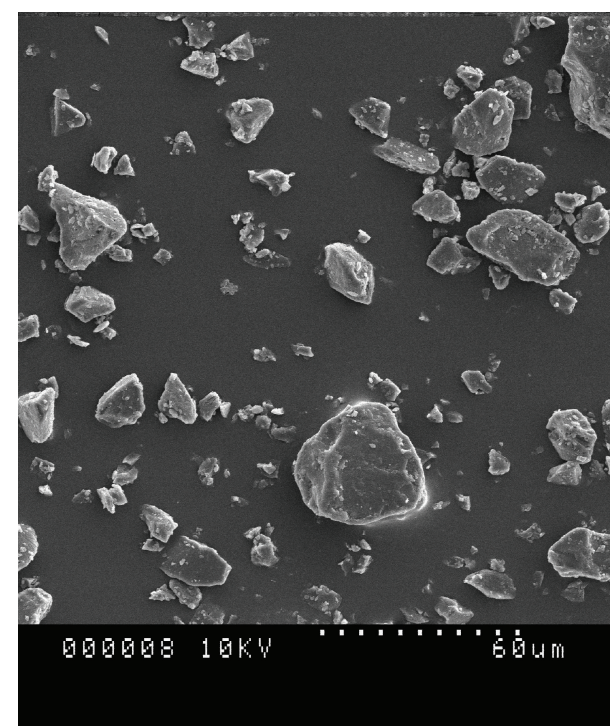

Figure 2: SEM image of Protobind 2400.

polymeric films made with lignin would be very interesting. The average particle size is around 10-15 micron meter. The SEM image of lignin (Figure 2) confirmed the OM image. The particle size is in the same range. The optical properties of lignin cannot be judged with scanning electron microscopy but the image is clearer with higher resolution.

PAN and PAN-Lignin Blends. Figure 3 shows the SEM image PAN polymer. The image was taken at 2500x magnification. The image is a typical polymer SEM figure. There is no void or failure point in the polymer. The neat polymer structure is well demonstrated in this SEM image. Rahman et al. [15] presents similar PAN structures in their SEM images. Rahman et al. [15] tried to make a new fiber without any pore using a new coagulation bath. In this study presented in this paper, it was also possible to obtain PAN materials without holes. Chen and Harrison [16] reports new carbon fibers using PAN and they made PAN fibers with holes as presented in their paper. This is another important aspect of this scientific paper to show that the author was successful in obtaining hole and void free PAN materials.

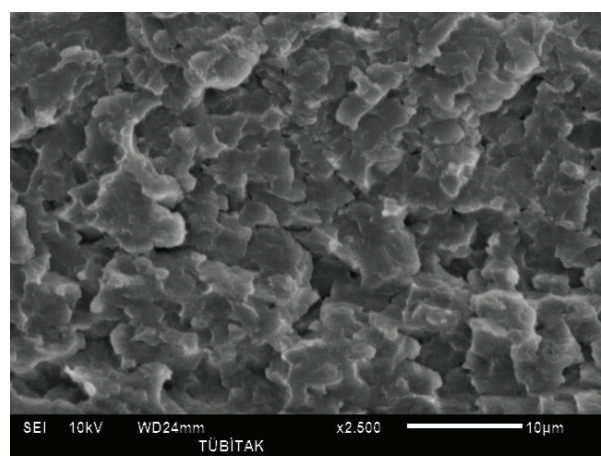

Figure 3: SEM image of PAN.

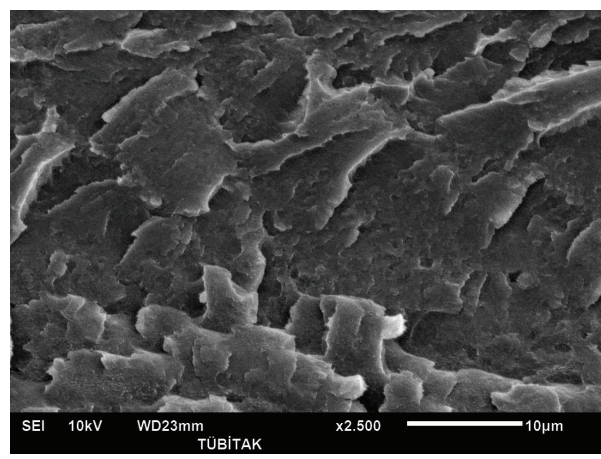

FIgURE 4: SEM image of PL2420.

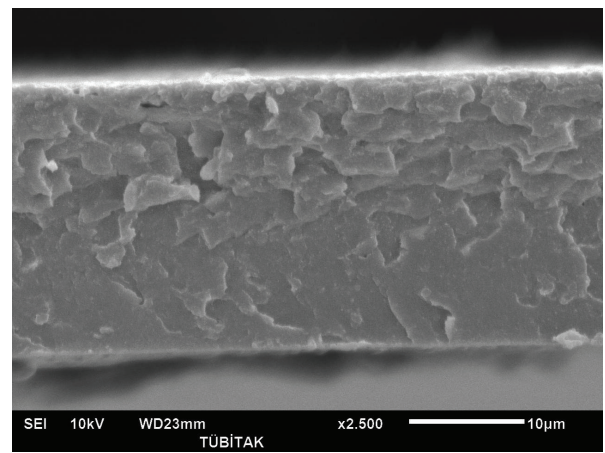

FIgURE 5: SEM image of PL5020.

Figures 4-6 show PAN and lignin blends with $20 \mathrm{wt} \%$ lignin. Figure 4 shows PAN blend with lignin Protobind 2400. Figure 5 shows PAN and lignin Protobind 5000 blend and Figure 6 shows PAN and lignin Protobind 1000. All the images are very important in terms of the compatibility and blend morphology. It is clearly observed that PAN and lignin blends form miscible blends with smooth surface and one phase figure. The lignin particles were dissolved in DMAc solvent with PAN so well that the particles of lignin are not visible any more like the OM and SEM images of the lignin. The blend morphologies are also very critical in the performance and compatibility of polymers. The blend morphologies are very homogenous and finely prepared. The similar observations were done by Zhang 


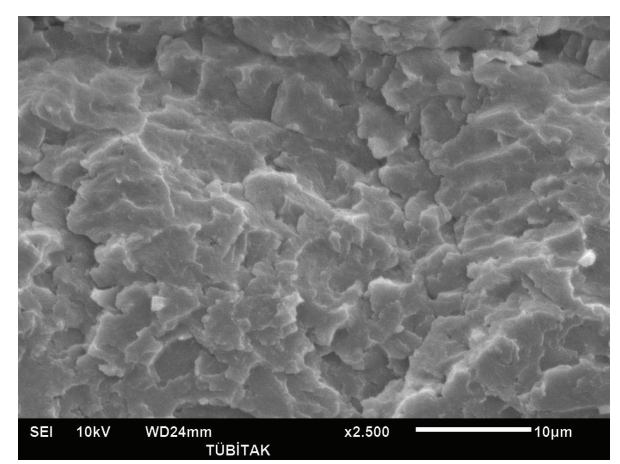

Figure 6: SEM image of PL1020.

TABLE 2: Modulus values.

\begin{tabular}{lcc}
\hline Sample code & $\begin{array}{c}\text { Storage modulus } \\
\text { values, } E^{\prime}\end{array}$ & $\begin{array}{c}\text { Loss modulus values, } \\
E^{\prime \prime}\end{array}$ \\
\hline PAN & $9.2 * 10^{8}$ & $5.1 * 10^{7}$ \\
PL1020 & $8.3 * 10^{8}$ & $4.2 * 10^{7}$ \\
PL2420 & $1.5 * 10^{9}$ & $1.1 * 10^{8}$ \\
PL5020 & $7.8 * 10^{8}$ & $6.3 * 10^{7}$ \\
PL2410 & $1.2 * 10^{9}$ & $8.2 * 10^{7}$ \\
PL2430 & $1.7 * 10^{9}$ & $3.1 * 10^{8}$ \\
\hline
\end{tabular}

et al. [17]. Though every blend looks very homogenous in shape, there are differences in the appearance of the lignin blends which arise from the lignin chemistry. Lignin blend with Protobind 2400 shows more brittle failure with sharper images. The lignin-PAN blend with Protobind 5000 looks smoother. The final blend morphology with Protobind 1000 looks more uniform which is very close to the image of the neat PAN. Protobind 2400 with higher purity leads to a sharp image whereas Protobind with certain functionalities creates a smooth PAN blend due to the chemical interaction of PAN and the nitrogen groups in lignin. Protobind 1000 series is less pure than Protobind 2400 and it does not have the functional groups. That is why the image is closer to neat PAN structure.

3.2. DMA Analysis. Dynamic mechanical analysis helps to understand the mechanical performance of the materials with regards to change in temperature [18-21]. The modulus values are plotted against increasing temperature with dynamic testing at $1 \mathrm{~Hz}$ frequency. The storage modulus value can be related to Young's Modulus measured during the static testing. The loss modulus value is related to modulus value of the material in the plastic deformation zone of tensile testing. Tan $\mathrm{d}$ is the ratio of loss modulus over storage modulus. A typical DMA curve is presented in Figure 7. This figure shows DMA graph of neat PAN material.

When the mechanical properties of neat PAN and PANlignin blends are investigated, it was observed that lignin does not deteriorate PAN properties (Table 2). When with Protobind 5000 and Protobind 1000, modulus values decrease slightly. The decrease for storage modulus values were $10 \%$ for Protobind 1000 and 15\% for Protobind 5000. On the other hand, when Protobind 2400 is used for PAN blending, the modulus values increase due to purity difference of the lignins. 2400 lignin is sulfur free lignin with better properties. The increase is linearly proportional as the lignin content increases. The rule of mixture can be applied here as stated in the following:

$$
\begin{aligned}
& E_{b}=E_{m} * V_{m}+E_{f} * V_{f}[22,23] \\
& E_{b} \text { is the modulus of the blend } \\
& E_{m} \text { is the modulus of matrix polymer (PAN) } \\
& V_{m} \text { is the volume fraction of matrix polymer } \\
& E_{f} \text { is the modulus of the fiber (lignin) } \\
& V_{f} \text { is the volume fraction of the fiber (lignin). }
\end{aligned}
$$

When the data is calculated from each concentration of lignin, the modulus value of lignin is calculated as $3.25 \mathrm{GPa}$ which is slightly higher than PAN and the value found in this study is confirming the previous studies done with lignin $[24,25]$. The previous studies showed that lignin has a modulus value of 3-5 GPa. Thus, the lignin material does not only lower the cost of PAN, it also improves the mechanical properties of PAN which will enable to increase the carbon fiber properties as well.

The loss modulus values of the neat PAN and blends follow the same trend as storage modulus values. As Protobind 1000 and Protobind 5000 are blended with PAN, the properties do not alter much but as Protobind 2400 is blended, the loss modulus values also increase parallel with storage modulus values.

Another important finding of this study was to utilize any kind of lignin for PAN studies in terms of mechanical properties. The properties of PAN do not alter much. This study can be even extended for lignin produced as the coproduct of paper industries and other industries.

3.3. FTIR. FTIR is a very powerful tool to understand the interactions of polymers and organic materials. Figure 8 shows FTIR analysis of PAN and PAN-Lignin blends. One of the important peak to mention is the band at $2243 \mathrm{~cm}^{-1}$ which corresponds to $\mathrm{C} \equiv \mathrm{N}$ bond [26]. There are three other important peaks for these analyses. The first peak is the $1430 \mathrm{~cm}^{-1}$ peak which disappears as the lignin is introduced and blends are formed. This peak corresponds to $\mathrm{CH}_{2}$ scissoring of PAN [27]. This shows the excellent interaction of PAN and lignin forming new bonds and altering the other bonds in the PAN structure.

The other two peaks that are noteworthy are the $1512 \mathrm{~cm}^{-1}$ and $1115 \mathrm{~cm}^{-1}$ peaks that are apparent as the PAN lignin blends are formed. $1512 \mathrm{~cm}^{-1}$ peak corresponds to $\mathrm{N}-\mathrm{H}$ bending of the lignins whereas $1115 \mathrm{~cm}^{-1}$ peak corresponds to $\mathrm{C}-\mathrm{H}$ stretching bond of the lignins [6]. As Protobind 2400 content increases, the intensity of peak at $1512 \mathrm{~cm}^{-1}$ increases. This shows that another important finding of this research was to find similar peaks even though the chemical content of these lignin differ. This shows that the major peaks of the lignin structure appeared in the PAN blends. Though, in literature, the exact structure of lignin 


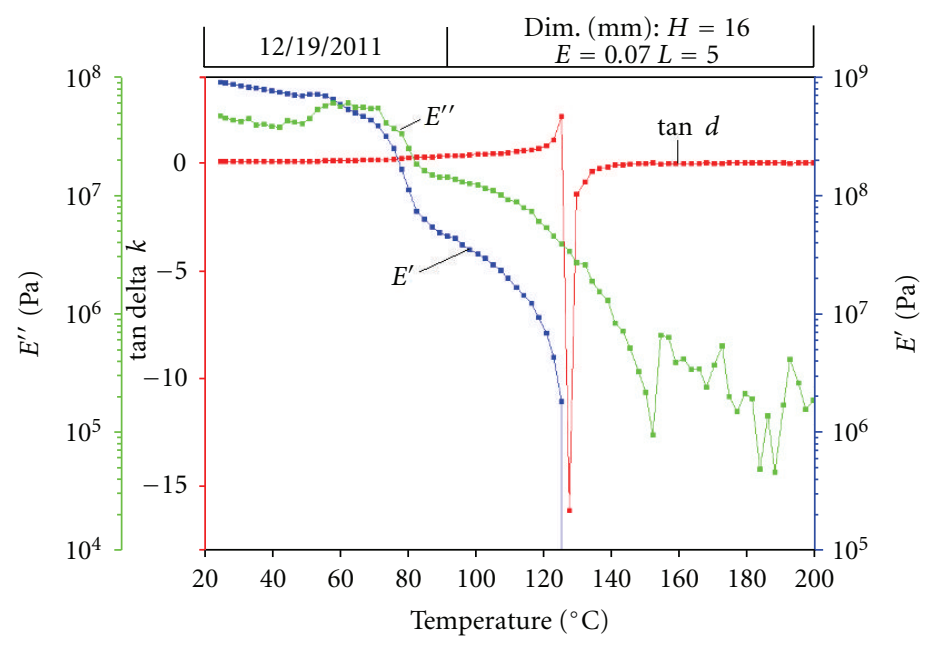

Figure 7: DMA curve.

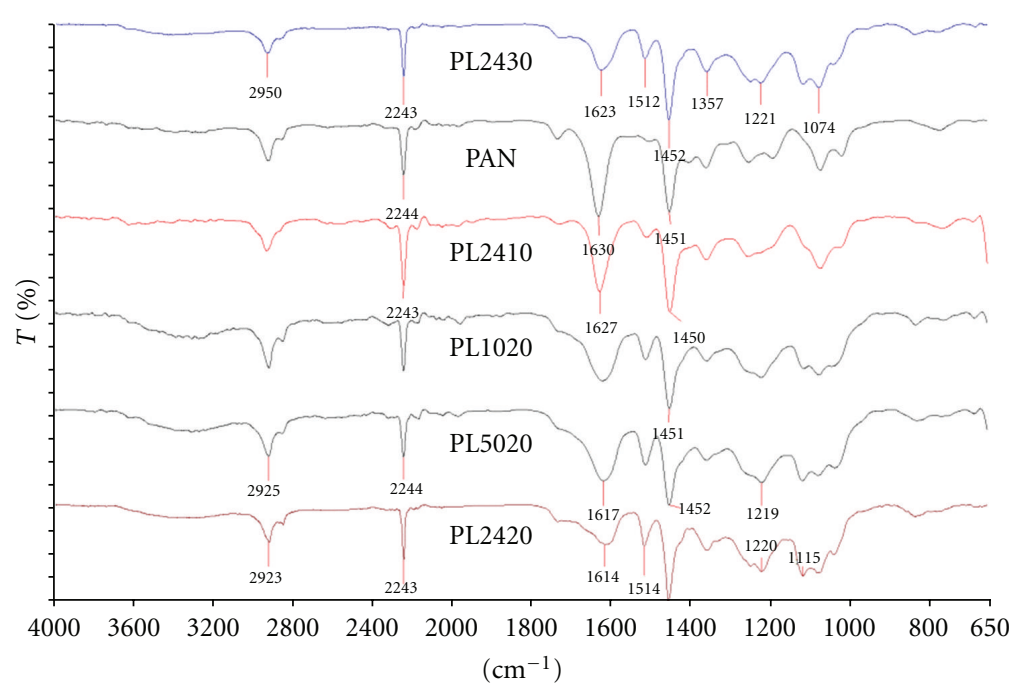

FIGURE 8: FTIR analysis of PAN and PAN-lignin blends.

could not be identified completely, there are studies showing important bonds of lignin $[6,8]$.

3.4. TGA. The thermal property of polymers is another important parameter. The thermal degradation occurs in polymeric materials at elevated temperatures. The polymer degrades at certain temperature. The degradation temperature is determined using the derivative of thermogravimetric analysis curve. At $300^{\circ} \mathrm{C}$, PAN started to decompose which can be observed from the thermal transition curves. Figure 9 shows the TGA curve without calculation and Figure 10 shows the calculated values. The PAN starts to decompose at $300^{\circ} \mathrm{C}$ with the first and major decomposition. In this degradation part, C-N bonds degrade [28, 29]. Around $426^{\circ} \mathrm{C}$, there is a second minor degradation temperature which would arise from $\mathrm{C}-\mathrm{C}$ bond breakage.

The influence of lignin for these transitions was investigated during this research. The previous publication on lignin characterization well documents the thermal stability of lignins [6]. The lignin material is not stable for high temperatures. The thermal stability of PAN decreases as the lignin content increases. TGA curve and derivative for the PAN2410 is demonstrated as an example of the study (Figure 11). The figures of all the blends are not shown to avoid too many graphs in the paper. The major degradation temperature of each blend is summarized in Table 3. The onset temperature for lignin decomposition of each lignin differs so the thermal stability of the PAN changes according to the lignin stability. Protobind 5000 was the least thermal stable lignin among others due to some alcohol and acid groups present in the material. The onset temperature of PAN with $5000(20 \mathrm{wt} \%)$ is lower than PL2430 which has $30 \mathrm{wt} \%$ of lignin 2400 . The finding of the thermal stability is also consistent with the data published in the author's previous paper [6].

More studies can be conducted at higher temperatures using TGA to understand the carbon fiber formation but 


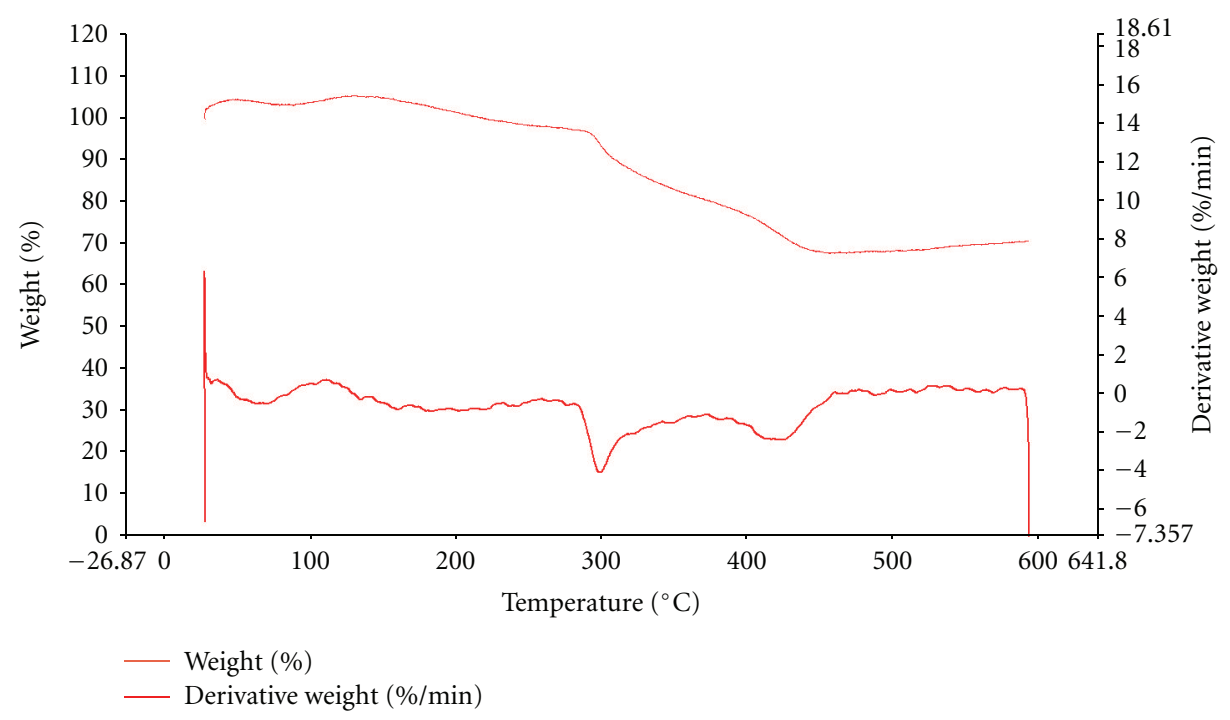

Figure 9: TGA-PAN.

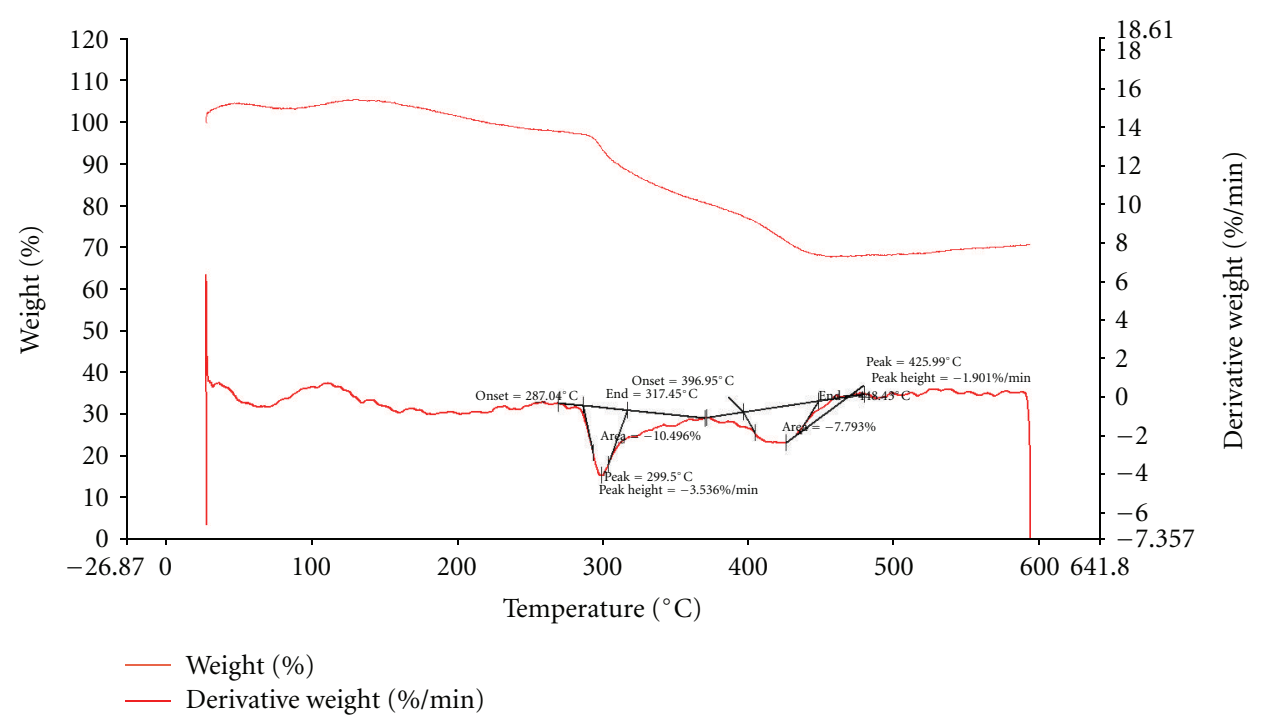

Figure 10: TGA-PAN, values determined.

TABle 3: Degradation temperatures.

\begin{tabular}{lc}
\hline Sample code & Degradation temperature \\
\hline PAN & 299.50 \\
PL1020 & 289.60 \\
PL2420 & 288.01 \\
PL5020 & 283.91 \\
PL2410 & 290.06 \\
PL2430 & 285.41 \\
\hline
\end{tabular}

this is beyond the limits of this study. During the next study, carbonization studies will be performed using the similar blends and at higher temperatures. This study is the first attempt to make polymer lignin blends to be used for carbon fiber precursor. These new findings will open new ways to understand the carbonization phenomena with lignin materials.

\section{Conclusion}

In this study, a very novel polymer was developed with a blend of PAN and a renewable resource material lignin. To meet the increased need for carbon fiber, there was a very limited research conducted to replace the precursor. There were two studies that prepared carbon fibers from lignin but the mechanical properties of the carbon fibers that were published could not be satisfactory to meet the requirements of the composite industry. In this preliminary study, it is observed that PAN can be replaced with lignin forming 


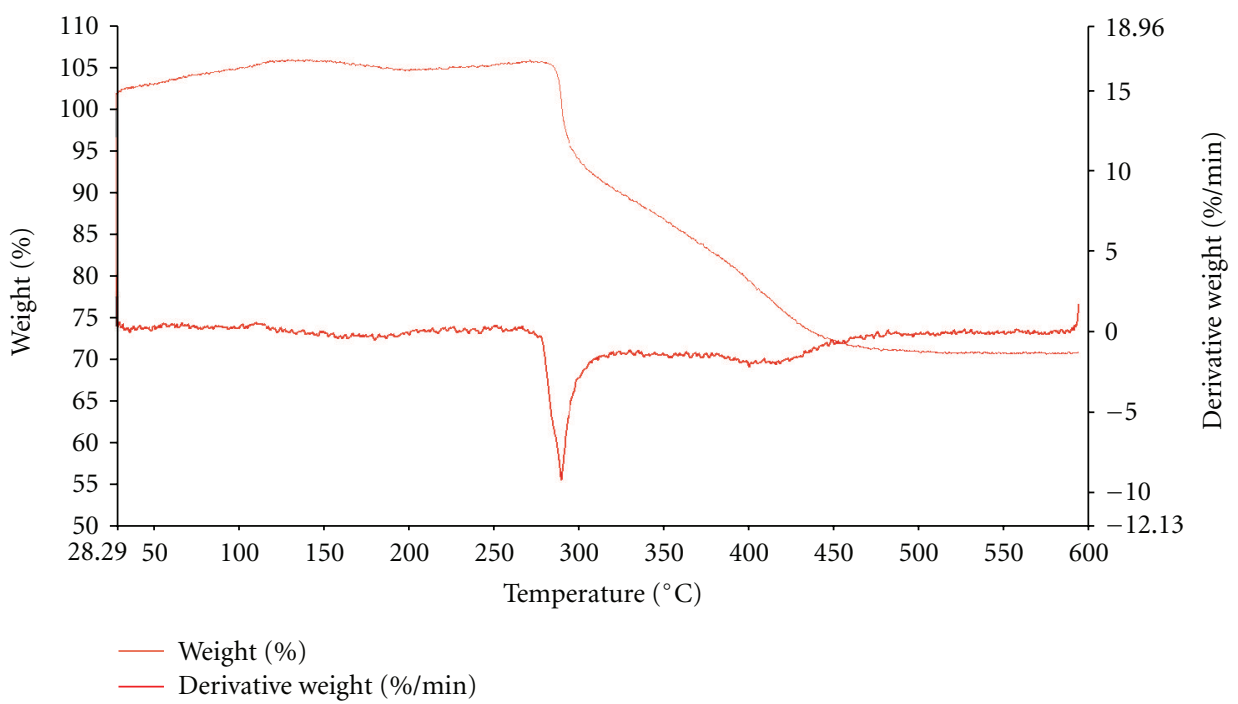

FIgURE 11: TGA-PL2410.

an excellent polymer blend without sacrificing the mechanical properties of PAN. The interaction of the PAN and lignin was observed with SEM, FTIR, and TGA analysis. This work with a homo-PAN demonstrated the initial steps for the PAN and carbon fiber industry. This study can be further carried with carbon fiber precursor, PAN and moreover that polymer blend can be spun to fiber and formed into carbon fiber via the carbonization processes. Most important part of the research was to utilize the lignin material which is an undervalued co-product of many different industries. This study demonstrated a new application area of lignin which is the second abundant matter on Earth after cellulose material. The most important finding of this research was to find a partial replacement of PAN with a renewable resource and making the PAN precursor greener technology to improve the world environment.

\section{Acknowledgments}

M. Seydibeyoğlu would like to express sincere thanks to Dr. Jairo Lora and Green value company for supplying the lignin materials as gift, Y. Seki for helping the FTIR and TGA analysis, G. Özkoç for DMA analysis, and Ö. Duygulu for helping to get SEM images. This paper has been prepared with their invaluable contributions.

\section{References}

[1] P. Morgan, Carbon Fibers and Their Composites, CRC Press, 2005.

[2] D. D. Edie, "Carbon fiber processing and structure/property relations," in Design and Control of Structure of Advanced Carbon Materials for Enhanced Performance, B. Rand, S. P. Appleyard, and M. F. Yardim, Eds., pp. 163-181, Kluwer Academic, Dodrecht, The Netherlands, 2001.

[3] D. D. Edie, "The effect of processing on the structure and properties of carbon fibers," Carbon, vol. 36, no. 4, pp. 345 $362,1998$.
[4] A. Wilson, Automotive Composites, from Steel to Carbon and from Glass to Grass, TMA Publishing, 2011.

[5] A. Forrest, J. Pierce, W. Jones, and E. Hwu, http://virtual .clemson.edu/caah/synergy/issue-1.htm.

[6] S. Sahoo, M. Ö. Seydibeyoğlu, A. K. Mohanty, and M. Misra, "Characterization of industrial lignins for their utilization in future value added applications," Biomass and Bioenergy, vol. 35, pp. 4230-4237, 2011.

[7] A. Mohanty, M. Ö. Seydibeyoğlu, S. Sahoo, and M. Misra, "Plant systems "Matching crops for bioproducts"," in Comprehensive Biotechnology, M. Moo-Young, Ed., vol. 4, pp. 101109, Elsevier, 2nd edition, 2011.

[8] M. N. S. Kumar, A. K. Mohanty, L. Erickson, and M. Misra, "Lignin and its applications with polymers," Journal of Biobased Materials and Bioenergy, vol. 3, no. 1, pp. 1-24, 2009.

[9] G. Xiao, M. Ni, R. Xiao, X. Gao, and K. Cen, "Catalytic carbonization of lignin for production of electrically conductive charcoal," Journal of Biobased Materials and Bioenergy, vol. 6, pp. 69-74, 2012.

[10] M. Ö. Seydibeyoğlu, M. Misra, and A. Mohanty, "New biobased polyurethane from soy plants and lignin," Bioplastics Magazine, vol. 5, p. 42, 2010.

[11] J. F. Kadla, S. Kubo, R. A. Venditti, R. D. Gilbert, A. L. Compere, and W. Griffith, "Lignin-based carbon fibers for composite fiber applications," Carbon, vol. 40, no. 15, pp. 2913-2920, 2002.

[12] K. Sudo and K. Shimizu, "New carbon fiber from lignin," Journal of Applied Polymer Science, vol. 44, no. 1, pp. 127-134, 1992.

[13] S. Bradbury and B. Bracegirdle, Introduction to Optical Microscopy, BIOS Scientific Publishers, 1998.

[14] L. Reimer and P. W. Hawkes, Scanning Electron Microscopy: Physics of Image Formation and Microanalysis, Springer Series in Optical Sciences, Springer, 2010.

[15] M. A. Rahman, A. F. Ismail, and A. Mustafa, "The effect of residence time on the physical characteristics of PAN-based fibers produced using a solvent-free coagulation process," Materials Science and Engineering A, vol. 448, no. 1-2, pp. 275280, 2007. 
[16] J. C. Chen and I. R. Harrison, "Modification of polyacrylonitrile (PAN) carbon fiber precursor via post-spinning plasticization and stretching in dimethyl formamide (DMF)," Carbon, vol. 40, no. 1, pp. 25-45, 2002.

[17] X. Zhang, S. Chen, J. Liu, Z. Hu, S. Chen, and L. Wang, "Preparation and properties of sulfonated poly(phenylene arylene)/sulfonated polyimide (SPA/SPI) blend membranes for polymer electrolyte membrane fuel cell applications," Journal of Membrane Science, vol. 371, no. 1-2, pp. 276-285, 2011.

[18] M. Özgür Seydibeyoǧlu and K. Oksman, "Novel nanocomposites based on polyurethane and micro fibrillated cellulose," Composites Science and Technology, vol. 68, no. 3-4, pp. 908914, 2008.

[19] M. O. Seydibeyoğlu, M. Misra, and A. Mohanty, "Synergistic improvements in the impact strength and \% elongation of polyhydroxybutyrate-co-valerate copolymers with functionalized soybean oils and POSS," International Journal of Plastics Technology, vol. 14, pp. 1-16, 2010.

[20] M. Ö. Seydibeyoğlu, S. Işçi, N. Güngör, O. I. Ece, and F. S. Güner, "Preparation of polyurethane/hectorite, polyurethane/ montmorillonite, and polyurethane/laponite nanocomposites without organic modifiers," Journal of Applied Polymer Science, vol. 116, no. 2, pp. 832-837, 2010.

[21] M. O. Seydibeyoğlu, "Excellent adhesion of carbon fibers to polyurethane matrix and substantial improvement of the mechanical properties of polyurethane," Gazi University Journal of Science, vol. 24, no. 3, pp. 501-506, 2011.

[22] W. Voigt, "Theoretische Studien über die Elasticitätsverhältnisse der Krystalle," Abhandlungen der Königlichen Gesellschaft der Wissenschaften in Göttingen, vol. 34, pp. 3-51, 1887.

[23] A. Reuss, "Berechnung der Fließgrenze von Mischkristallen auf Grund der Plastizitätsbedingung für Einkristalle," Journal of Applied Mathematics and Mechanics, vol. 9, pp. 49-58, 1929.

[24] T. Elder, "Quantum chemical determination of young's modulus of lignin. Calculations on a $\beta-0-4$ ' model compound," Biomacromolecules, vol. 8, no. 11, pp. 3619-3627, 2007.

[25] C. K. Hong and R. F. Wool, "Development of a bio-based composite material from soybean oil and keratin fibers," Journal of Applied Polymer Science, vol. 95, no. 6, pp. 15241538, 2005.

[26] Q. Ouyang, L. Cheng, H. Wang, and K. Li, "Mechanism and kinetics of the stabilization reactions of itaconic acid-modified polyacrylonitrile," Polymer Degradation and Stability, vol. 93, no. 8, pp. 1415-1421, 2008.

[27] I. Spiridon, C. A. Teaca, and R. Bodirlau, "Structural changes evidenced by FTIR spectroscopy in cellulosic materials after pre-treatment with ionic liquid and enzymatic hydrolysis," Bioresources, vol. 6, pp. 400-413, 2010.

[28] T. Yu, J. Lin, J. Xu, T. Chen, S. Lin, and X. Tian, "Novel polyacrylonitrile/Na-MMT/silica nanocomposite: Co-incorporation of two different form nano materials into polymer matrix," Composites Science and Technology, vol. 67, no. 15-16, pp. 3219-3225, 2007.

[29] N. Şahiner, N. Pekel, and O. Güven, "Radiation synthesis, characterization and amidoximation of N-vinyl-2-pyrrolidone/acrylonitrile interpenetrating polymer networks," Reactive and Functional Polymers, vol. 39, no. 2, pp. 139-146, 1999. 

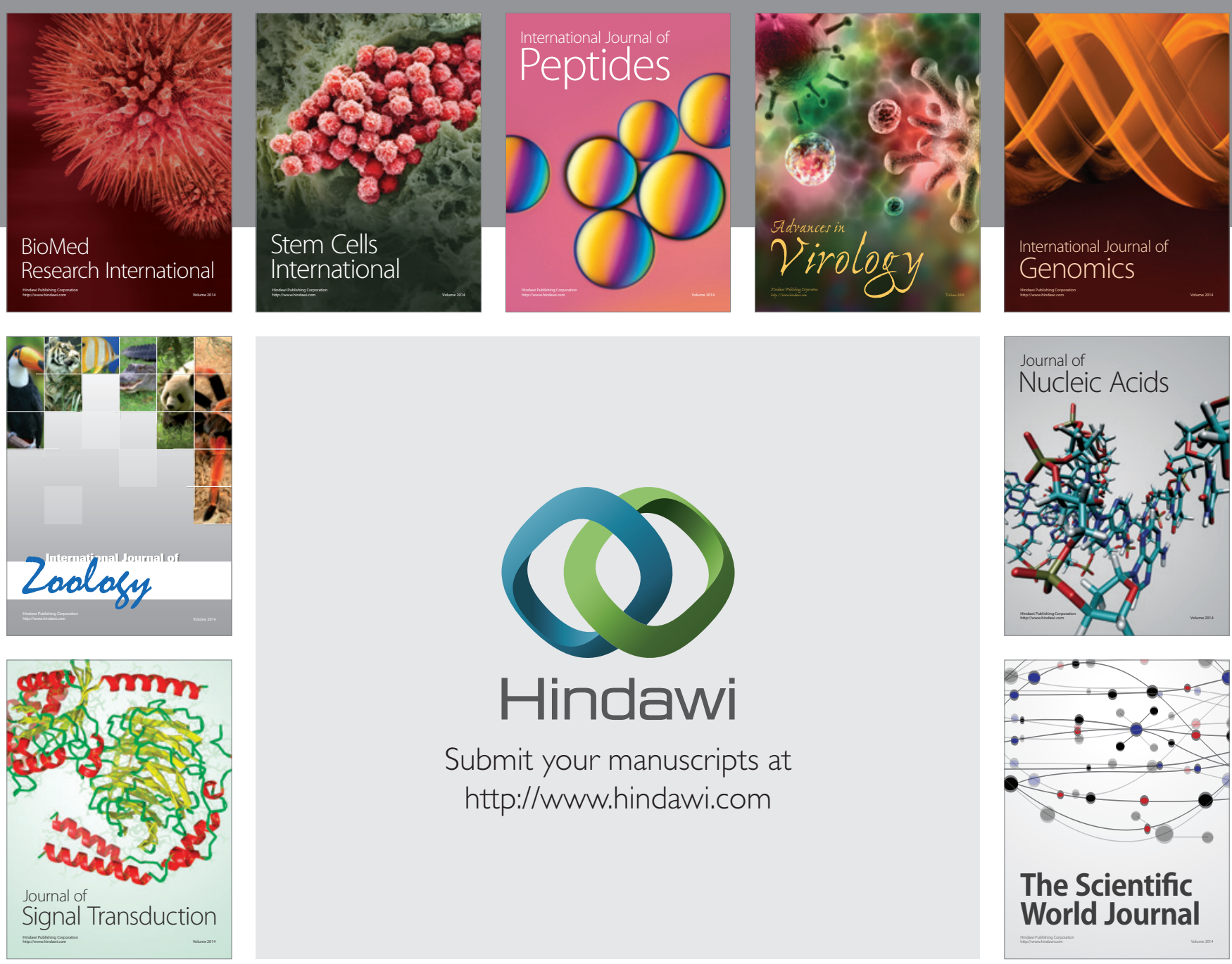

Submit your manuscripts at

http://www.hindawi.com
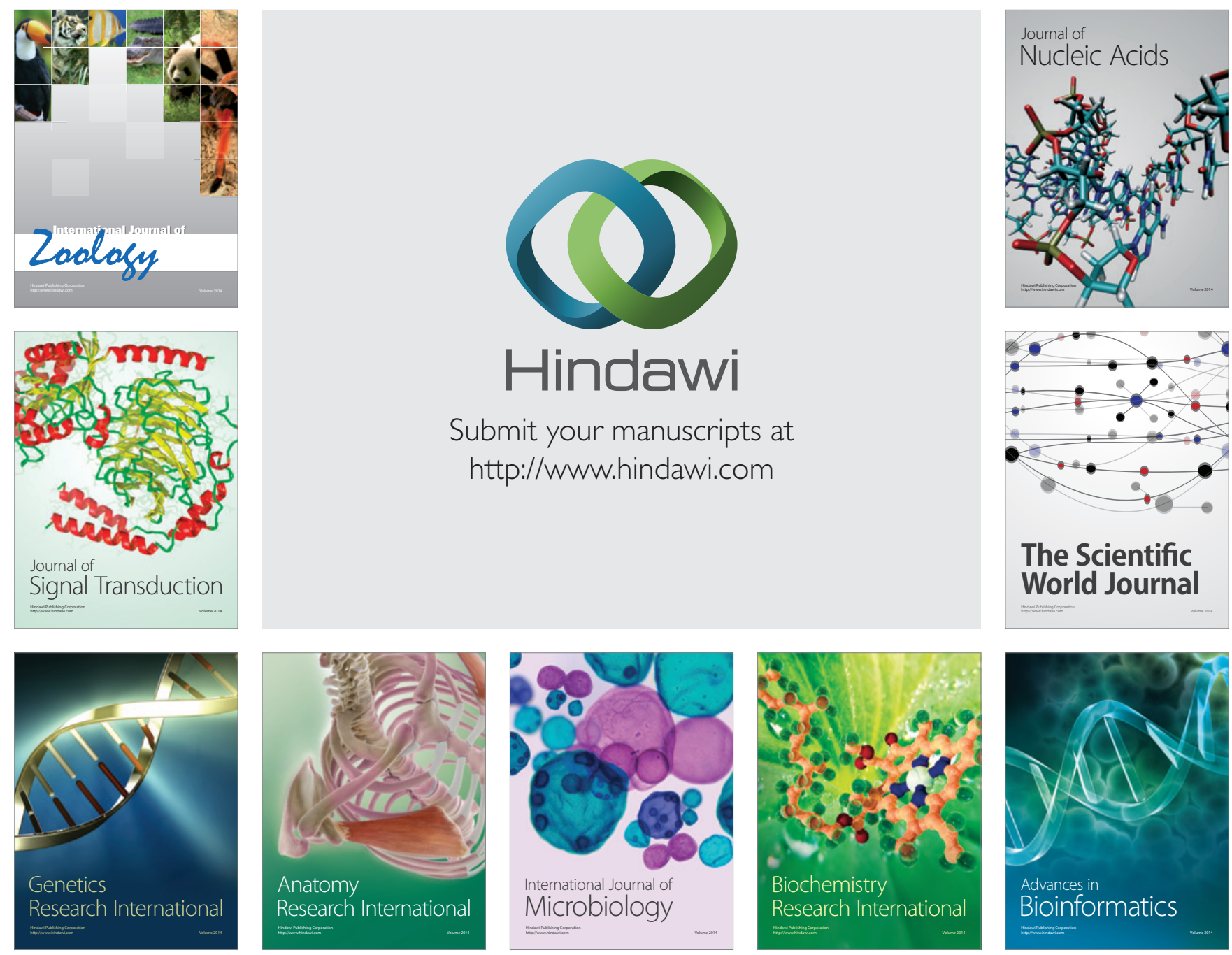

The Scientific World Journal
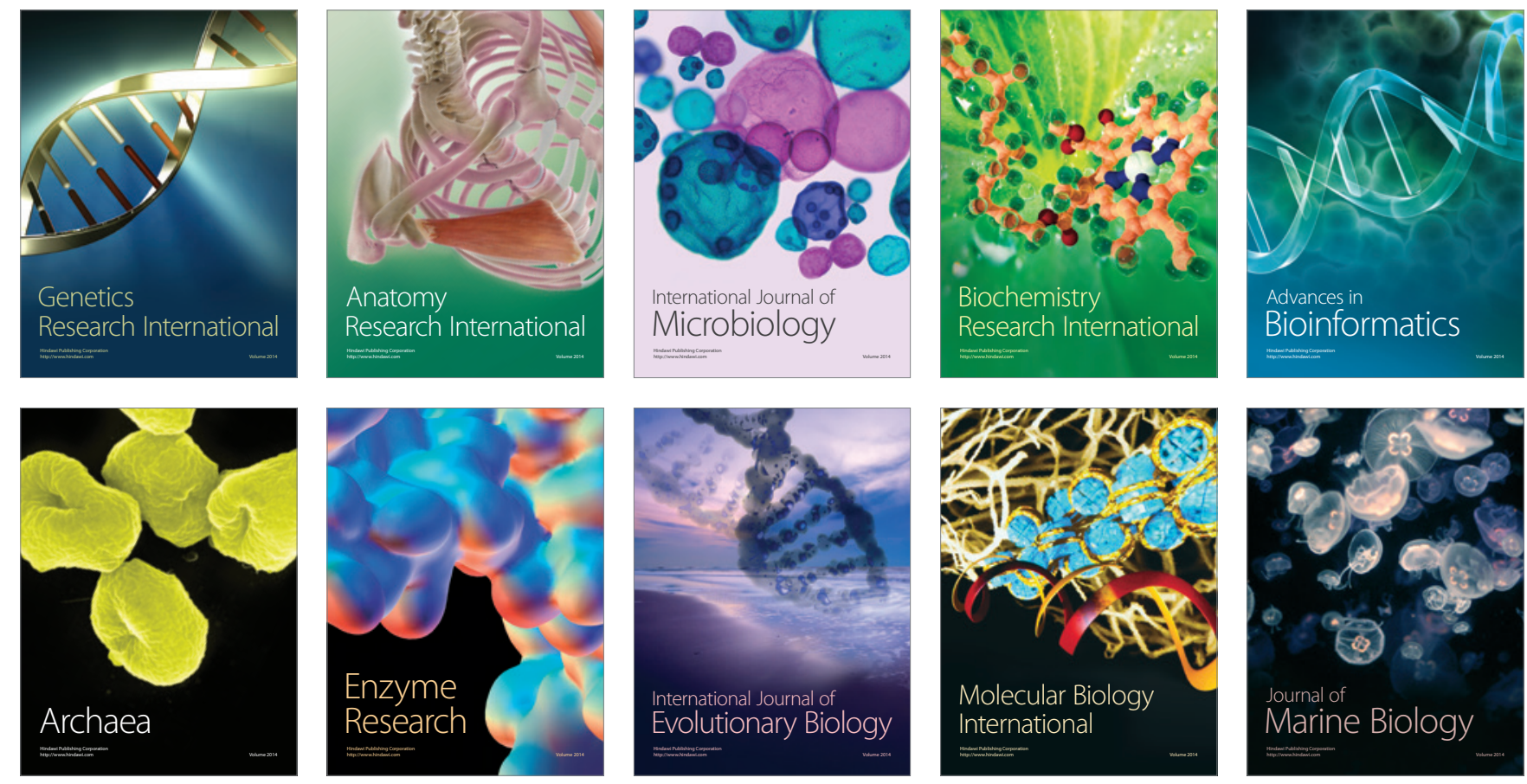